Case Report

\title{
Epidermoid Causing Ischemic Stroke in the Brainstem
}

\author{
Raghvendra Ramdasi, ${ }^{1}$ Amit Mahore, ${ }^{1}$ Abhijeet Kulkarni, ${ }^{1}$ Vithal Rangarajan, ${ }^{1}$ \\ Manoj Patil, ${ }^{1}$ and Juhi Kawale ${ }^{2}$ \\ ${ }^{1}$ Department of Neurosurgery, King Edward Memorial Hospital and Seth Gordhandas Sunderdas Medical College, \\ Parel, Mumbai 400012, India \\ ${ }^{2}$ Department of Medicine, King Edward Memorial Hospital and Seth Gordhandas Sunderdas Medical College, \\ Parel, Mumbai 400012, India \\ Correspondence should be addressed to Raghvendra Ramdasi; drraghavr@gmail.com
}

Received 14 October 2014; Accepted 1 December 2014; Published 15 December 2014

Academic Editor: José Luis González-Gutiérrez

Copyright (C) 2014 Raghvendra Ramdasi et al. This is an open access article distributed under the Creative Commons Attribution License, which permits unrestricted use, distribution, and reproduction in any medium, provided the original work is properly cited.

Intracranial tumors may rarely cause stroke. We report an epidermoid cyst causing stroke in a pediatric patient. We have also reviewed the literature and pathogenesis of stroke caused by intracranial tumors.

\section{Introduction}

Stroke as a presenting symptom of intracranial tumors is extremely rare. Epidermoids referred to as "an ordered disorder" usually produce symptoms of slowly progressive mass lesion [1]. We report a pediatric case of brainstem infarct caused by this "well mannered" epidermoid tumor in cerebellopontine angle. This phenomenon was only once reported in adults [2].

\section{Case Presentation}

A 12-year-old boy was brought by parents into a rural hospital with complaint of headache for the last 6 months. Computed tomography (CT) scan of brain revealed a hypodense lesion in right cerebellopontine angle and basal cistern (Figure 1(a)). The provisional diagnoses were arachnoid cyst and epidermoid cyst. The patient was referred to tertiary care centre for further management as neurosurgical and magnetic resonance imaging (MRI) facilities were not available at the rural hospital. However, the parents did not follow the medical advice. He was brought to our emergency department after 5 months when he developed altered sensorium and left hemiparesis of sudden onset. On examination, the patient was drowsy and not obeying commands. The patient had good spontaneous activity of right sided limbs without any spontaneous movements of left sided limbs. There was definite paucity of movements of left sided limbs to the central painful stimuli as compared to those of the right sided limbs. The exact assessment of weakness was not possible due to the drowsy state. The right pupil was larger as compared to the left pupil and was not reacting to light. The left sided limbs had hyperreflexia. The left plantar reflex showed extensor response. The rest of the findings were unremarkable.

Magnetic resonance imaging (MRI) of the brain was done within one hour of arrival of the patient and approximately 12 hours after the onset of symptoms. It revealed the lesion with isointensity on T1 weighted imaging and hyperintensity on T2 weighted imaging in right cerebellopontine angle extending to basal cistern (Figures 1(b) and 1(c)). There was another lesion in right half of midbrain with hyperintensity on $\mathrm{T} 1$, T2, and FLAIR images (Figures $1(\mathrm{~d}), 1(\mathrm{e}), 1(\mathrm{f})$, and $1(\mathrm{~g})$ ), restricting diffusion on diffusion weighted image (DWI) like the first lesion (Figure 1(h)). The lesion showed low signal on apparent diffusion coefficient (ADC) map ruling out T2 shine-through effect. These findings were suggestive of right cerebellopontine angle epidermoid with right midbrain infarct. The restriction of diffusion on DWI ruled out the possibility of arachnoid cyst. His other investigations including coagulation profile and electrolytes were normal.

The patient was operated on, on emergency basis via right retrosigmoid approach, and near-complete excision 


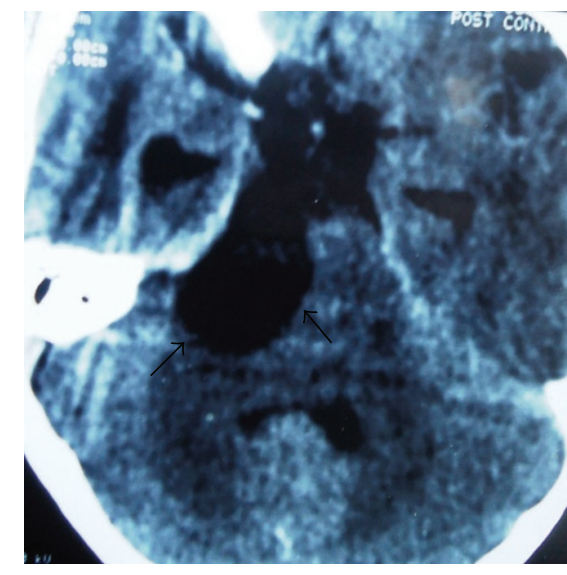

(a)

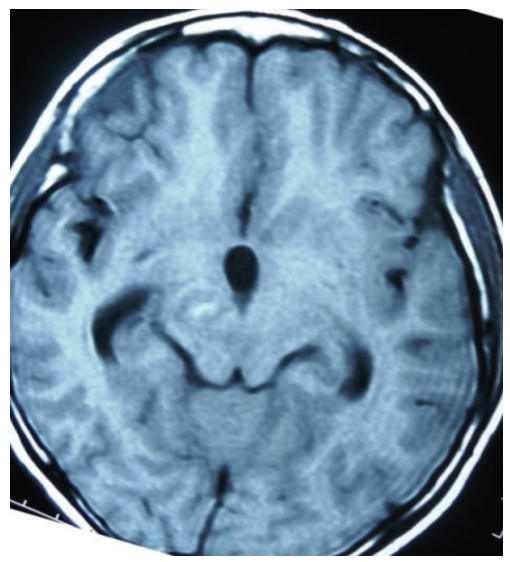

(d)

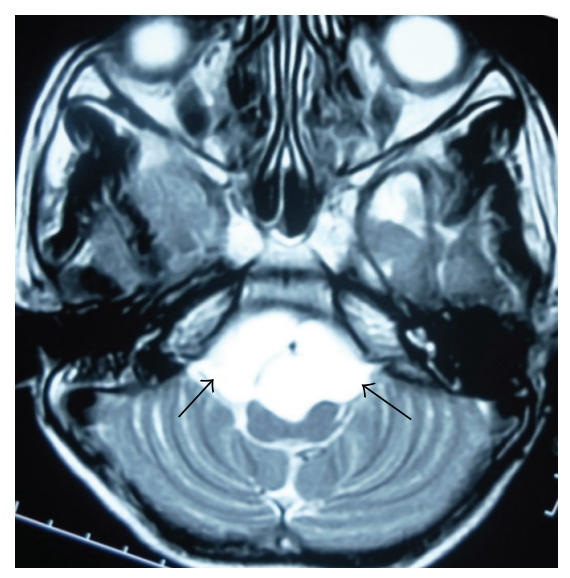

(b)

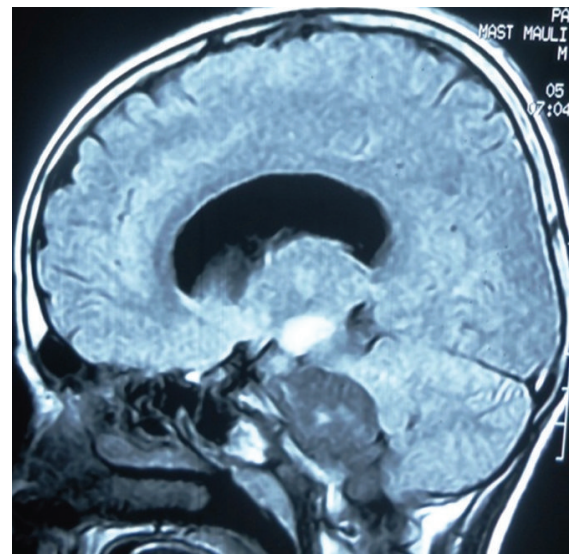

(e)

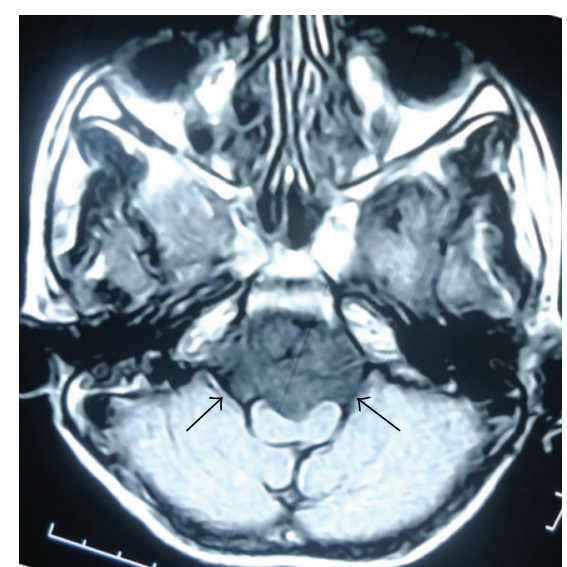

(c)

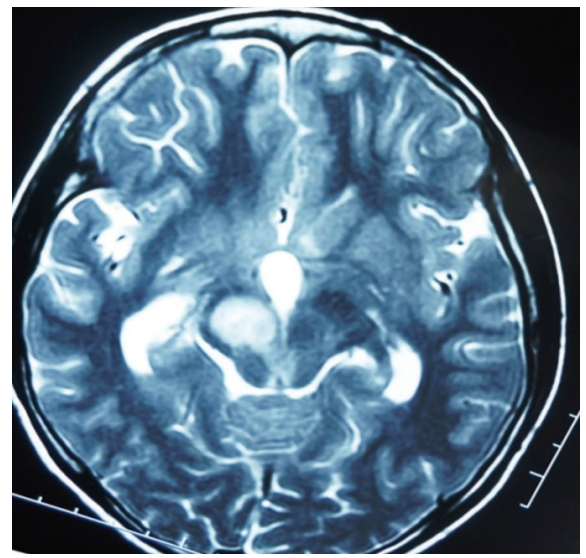

(f)

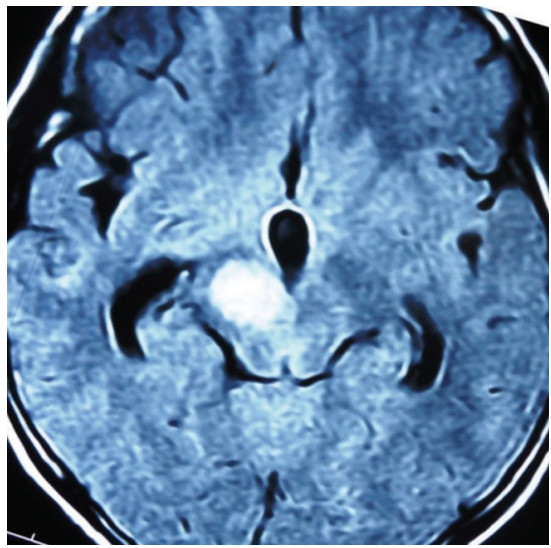

(g)

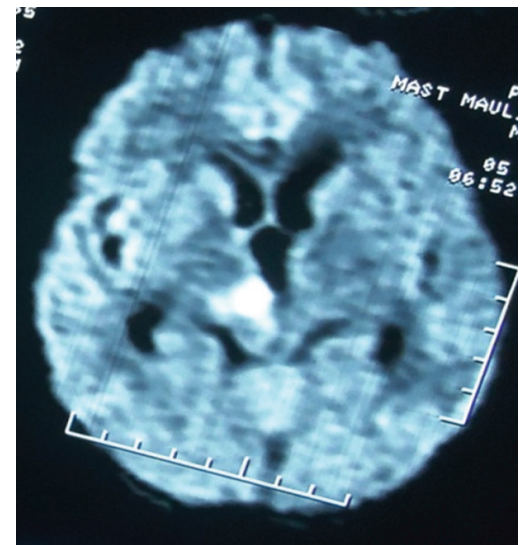

(h)

Figure 1: (a) Axial image of plain computed tomography (CT) showing hypodense lesion in right cerebellopontine angle and prepontine cistern with compression of the brainstem. Axial T2 (b) and T1 (c) weighted MR images showing the lesion to be hypointense on T1 and hyperintense on T2 sequence (black arrows outline the tumour). (d) and (e) are T1 weighted axial and sagittal images. (f), (g), and (h) are axial T2, FLAIR, and diffusion weighted images, respectively, revealing another lesion of hyperintensity and restricted diffusion in right half of midbrain. 


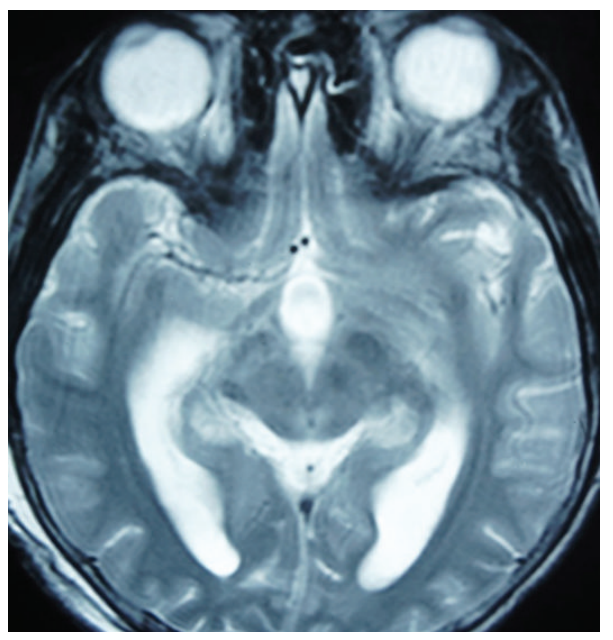

(a)

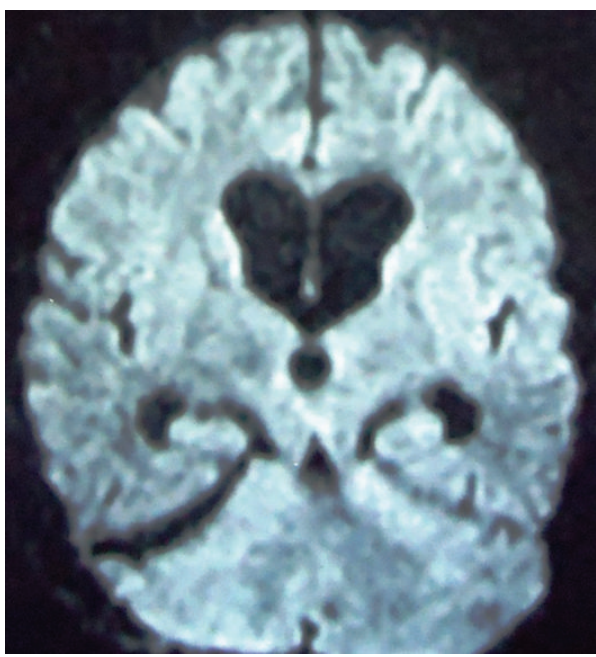

(c)

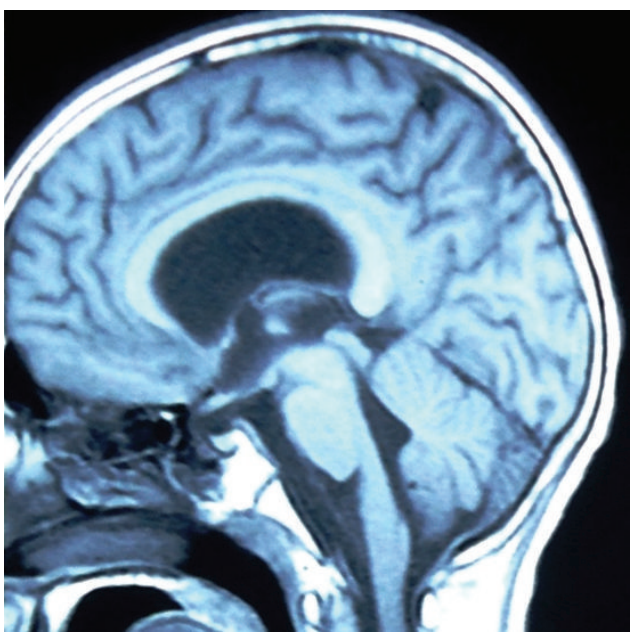

(b)

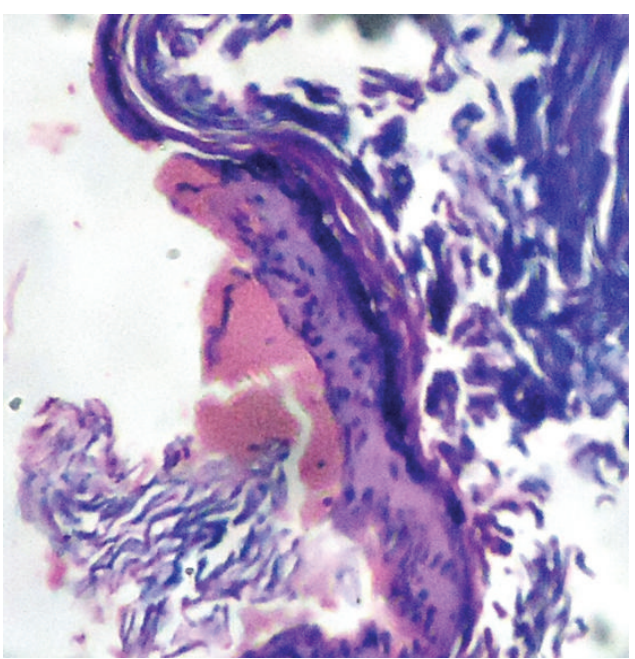

(d)

Figure 2: (a) Axial T2, sagittal T1 (b), and diffusion weighted postoperative image (c) showing complete excision of the lesion and resolution of the infarct. (d) The photomicrograph of the lesion $(\mathrm{H} \& \mathrm{E}, 100 \mathrm{x})$ showing stratified squamous lining epithelium with lamellated keratin.

of epidermoid cyst was done leaving behind the capsular fragments densely adherent to vessels and nerves.

The patient improved in sensorium with partial improvement of hemiparesis after the surgery. Magnetic resonance imaging (MRI), done one month after the surgery, was suggestive of complete resolution of the infarct (Figures 2(a), 2(b), and 2(c)). Histopathological examination revealed the lesion lined by stratified squamous epithelium with lamellated keratinconsistent with epidermoid cyst (Figure 2(d)). At follow-up of 1 year after the surgery he was completely normal.

\section{Discussion}

Schnitker and Lehnert in 1952 described middle cerebral artery infarct in a case of pituitary apoplexy [3]. There are few cases of intracranial tumors causing infarct, the mechanisms of which differ from each other [2]. Pituitary adenoma is the most common benign tumor causing infarct. These encase the vessels and compress them subsequently. Infrequently these may cause vasospasm [2, 4]. Meningiomas cause infarct by compression of the vessels [5]. Malignant gliomas cause infarct by invasion of vessels [6-8]. Ruptured dermoid cyst results in vasospasm and infarct $[9,10]$. One case of ruptured craniopharyngeal cyst causing infarct is reported and vasospasm is the implicated mechanism [11].

Epidermoids account for approximately $1 \%$ of all intracranial tumors. Although these lesions are congenital, patients are usually symptomatic in their third to fifth decade [12]. Two cases of epidermoid causing brainstem infarct were reported where stretching of the vessel was the postulated mechanism [2]. It is likely that the tumor in our case stretched one or more branches of the basilar artery leading to the infarct.

In all the cases reviewed, we found only one pediatric case described by Pozzati et al. [13]. Our case is the second paediatric case of tumors causing infarct and the youngest 
one. It is the first pediatric case and the third case of epidermoid causing infarct.

T1 hyperintensity with no blooming on gradient echo as in our case may represent incomplete stroke as described by Baheti et al. and warrant urgent intervention [14].

The two cases described before were treated medically for two weeks and the postoperative improvement in their deficits is not mentioned [2]. In our case we operated on the patient within 16 hours of the ictus and he improved remarkably in his deficits. We did not give antiplatelet treatment to our patient because surgery was anticipated in our case. The use of antiplatelets is known to increase the incidence of hematoma in major neurosurgical procedures.

\section{Conclusion}

Epidermoids may cause acute symptoms as brainstem infarct. The exact mechanism is unknown, but the stretching of the vessels may play an important role. Early surgery instead of medical treatment can reverse the insult. When primary cause of stroke is tumor or tumor-like lesion, the early surgery rather than antiplatelet treatment should be considered.

\section{Conflict of Interests}

The authors declare that there is no conflict of interests regarding the publication of this paper.

\section{Authors' Contribution}

Each author has contributed in management of patient, review of literature, and/or preparation of the paper.

\section{References}

[1] M. Kothari and A. Goel, "The heuristics of craniospinal epidermoid tumors," Neurology India, vol. 54, no. 2, p. 143, 2006.

[2] S. Yilmazlar, H. Kocaeli, and T. Cordan, "Brain stem stroke associated with epidermoid tumours: report of two cases," Journal of Neurology, Neurosurgery and Psychiatry, vol. 75, no. 9, pp. 1340-1342, 2004.

[3] M. T. Schnitker and H. B. Lehnert, "Apoplexy in a pituitary chromophobe adenoma producing the syndrome of middle cerebral artery thrombosis; case report," Journal of Neurosurgery, vol. 9, no. 2, pp. 210-213, 1952.

[4] S. Mohindra, P. Kovai, and R. Chhabra, "Fatal bilateral ACA territory infarcts after pituitary apoplexy: a case report and literature review," Skull Base, vol. 20, no. 4, pp. 285-288, 2010.

[5] S. Mathis, B. Bataille, S. Boucebci et al., "A rare cause of stroke in young adults: occlusion of the middle cerebral artery by a meningioma postpartum," Case Reports in Neurological Medicine, vol. 8, pp. 652-653, 2013.

[6] P. E. Kaplan, R. Santana, J. Cohen, and J. Leestma, "Glioblastoma multiforme presenting as stroke: an electrophysiological and clinicopathological case report," Archives of Physical Medicine and Rehabilitation, vol. 60, no. 2, pp. 74-77, 1979.

[7] E. Auff and K. Vass, "Cerebellar glioblastoma presenting clinically as Wallenberg's syndrome," Archiv für Psychiatrie und Nervenkrankheiten, vol. 230, no. 4, pp. 361-364, 1981.
[8] H. Chen, H. Cebula, R. Schott, J.-L. Dietemann, and S. Froelich, "Glioblastoma multiforme presenting with ischemic stroke: case report and review of the literature," Journal of Neuroradiology, vol. 38, no. 5, pp. 304-307, 2011.

[9] M. G. Kang, K. J. Kim, J. I. Seok, and D. K. Lee, "Intracranial dermoid cyst rupture with midbrain and thalamic infarction.", Neurology, vol. 72, no. 8, p. 769, 2009.

[10] J. M. Ramírez-Moreno, M. Ortega-Martínez, M. A. FernándezGil et al., "Isolated mesencephalic stroke related to a ruptured intracranial dermoid cyst," Neurocirugia, vol. 20, no. 3, pp. 272277, 2009.

[11] N. Shida, N. Nakasato, K. Mizoi, M. Kanaki, and T. Yosimot, "Symptomatic vessel narrowing caused by spontaneous rupture of craniopharyngioma cyst-case report," Neurologia MedicoChirurgica, vol. 38, no. 10, pp. 666-668, 1998.

[12] N. Oulali, F. Moufid, M. R. Ghailan, and B. Hosni, "Epidermoid cyst of the cisterna magna and fourth ventricle," Pan African Medical Journal, vol. 13, article 19, 2012.

[13] E. Pozzati, G. Frank, M. T. Nasi, and G. Giuliani, "Pituitary apoplexy, bilateral carotid vasospasm, and cerebral infarction in a 15-year-old boy," Neurosurgery, vol. 20, no. 1, pp. 56-59, 1987.

[14] N. N. Baheti, A. Cherian, W. P. R. C. Kesavadas, and B. Thomas, "Ischemic hyperintensities on T1-weighted magnetic resonance imaging of patients with stroke: New insights from susceptibility weighted imaging," Neurology India, vol. 58, no. 1, pp. 90-94, 2010. 


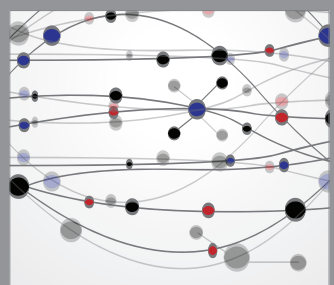

The Scientific World Journal
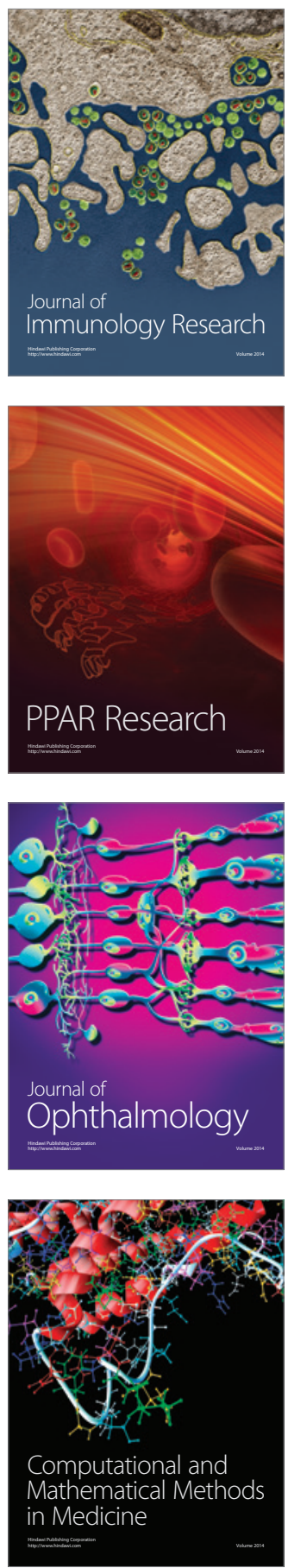

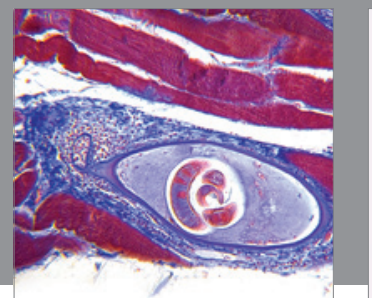

Gastroenterology

Research and Practice
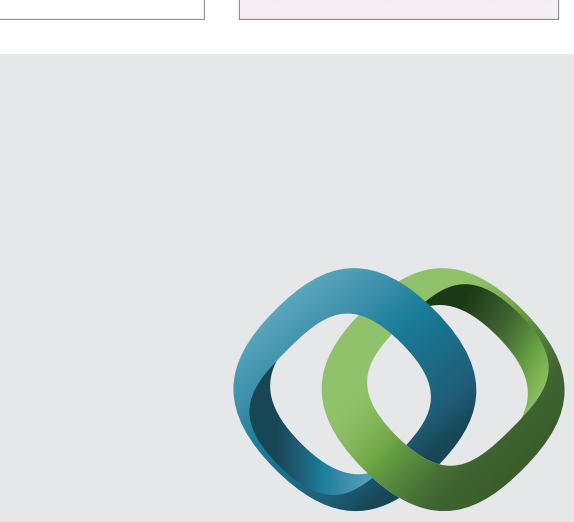

\section{Hindawi}

Submit your manuscripts at

http://www.hindawi.com
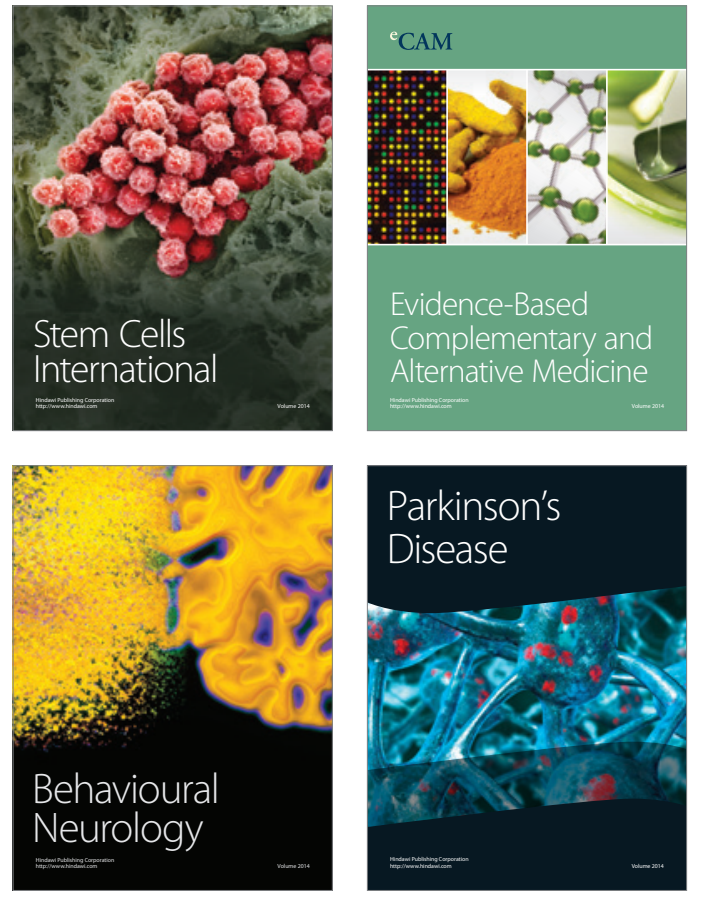
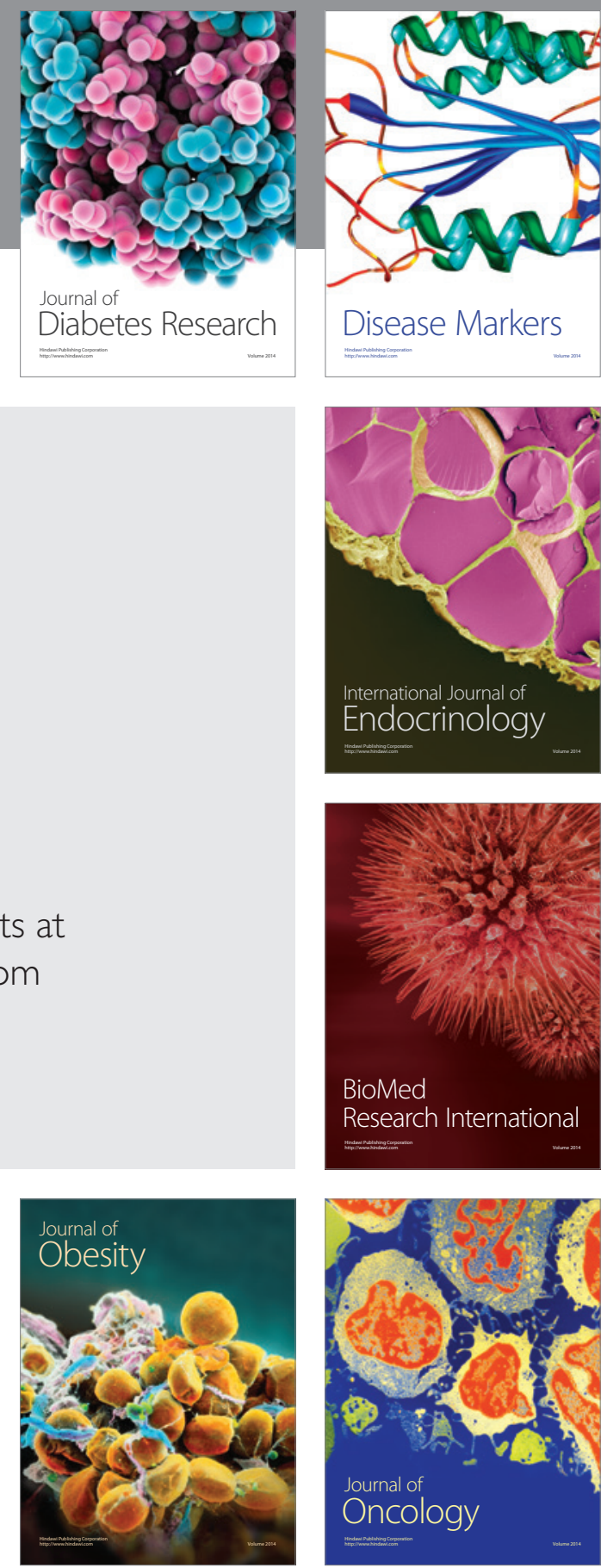

Disease Markers
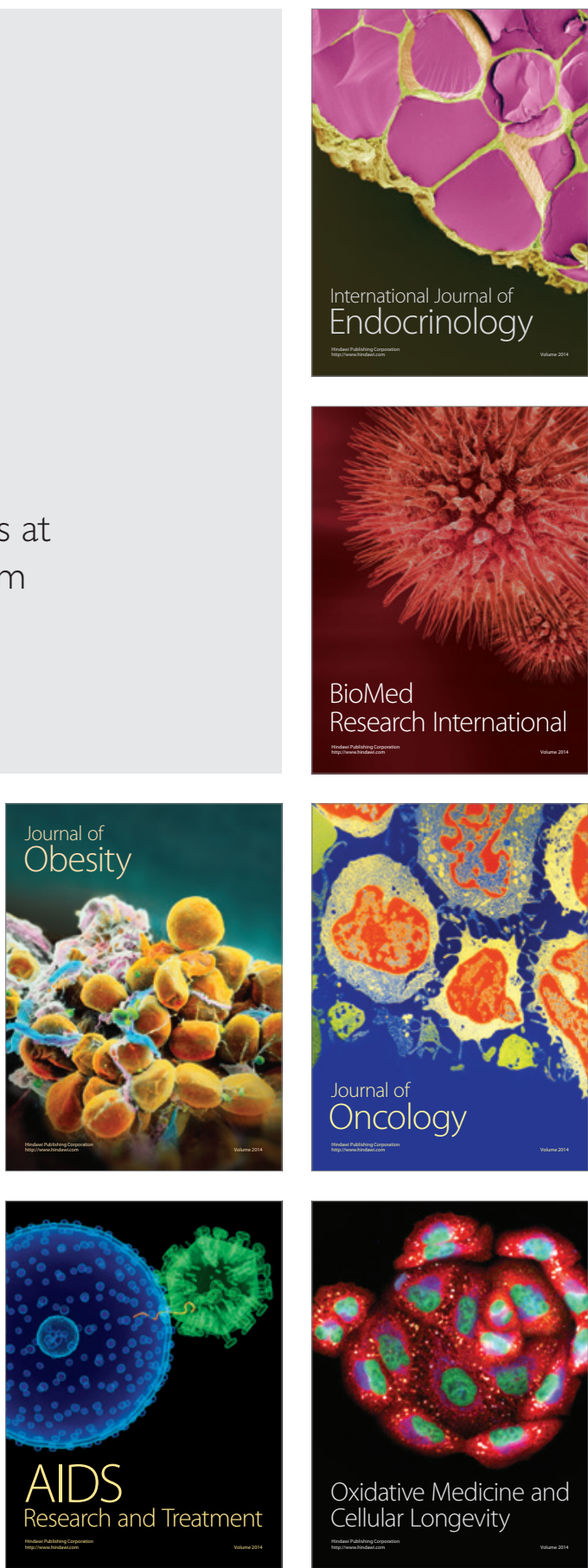